\title{
Using Calls And Puts As Risk Management Tools
}

Ducksang Choi, (E-mail: choid@mscd.edu), Metropolitan State College of Denver

\begin{abstract}
A very strong case is presented for why the financial manager of an electric utility company should use hedging strategies to ensue a continuous supply of natural gas to his/her utility. A combination of hedging strategies has been presented and tested for the natural gas market. The combination of strategies works and works well while substantially reducing risk at the same time.
\end{abstract}

\section{INTRODUCTION}

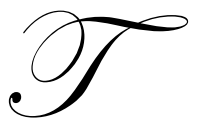

he area of energy risk management is an extremely complicated multi-faceted area as evidenced by the 260 pages compendium of articles on this subject with the title Energy Risk Management edited by Peter C. Fusaro. This paper presents an overview of this field drawing freely from the many articles in this book and supplementing them to bring them up to date, and then narrows down to one specific problem: If a financial analyst/manager for an electric utilities company was confronted with the problem of insuring his/her utility adequate natural gas supplies, what strategies would he/she use to minimize risk and make some profit to offset the high costs? The time history of near term futures during this period will be presented and analyzed. The specific buying, selling, and hedging strategies for natural gas futures and futures options will be presented that are necessary to insure not only an adequate supply to the electric utility, but also to take advantage of the profit making possibilities. A quantitative example is given for a utility requiring $100 \mathrm{MMBtu} / \mathrm{month}$ of natural gas.

\section{SYNOPSIS OF THE PRESENT SITUATION FOR ELECTRIC UTILITIES}

Electric utilities are in the process of being deregulated. The US Public Utility Regulatory Act (PURA) of 1978 was a sweeping piece of legislation that marked the transition to a wholesale competitive market. It was designed as a set of incentives for improving fuel use efficiency through cogeneration and the use of renewable resources that required electric utilities to interconnect with and purchase power from certain small producers known as qualifying facilities. In the years immediately following PURA, the growth of non-utility generation was slow due to economic uncertainty and legal challenges. However, through the 1980s, non-utility generation became one of the fastest-growing segments of the industry. By 1992, their combined sale was reported at over 166 billion kW, a number that far exceeded wholesale purchases for investor-owned utilities in the entire Western System Coordinating Council. Investor-owned utilities constitute more than $80 \%$ of the power generation capacity of the United States.

The successes of this experiment convinced the US government of the feasibility of outright competition in the continental United States. In 1992, Congress enacted the Electric Policy Act that removed the remaining barriers to wholesale competition. Since then, the industry has seen a major escalation in market activities that has astounded even the most ardent proponents of deregulation.

A direct consequence of the Energy Policy Act in 1992 was the advent of a whole new generation of businesses created solely for the purpose of marketing electric power. Commonly known as 'power marketers,' these businesses have little or no assets tied to the generation and transmission of electric energy. Under the US Federal Powers Act, a power marketer is a public utility that is subject to Federal Regulatory Commission (FERC) 
regulation. As a prerequisite for transacting in wholesale energy across state lines, a power marketer must file a market-based rate schedule with the FERC.

The first generation of power marketers came, for the most part, from the Natural Gas Industry. With over a decade of experience marketing natural gas to electric utilities, these companies had both the infrastructure and the marketing expertise necessary to face the complexities of the burgeoning electricity markets. Although not taken seriously initially, attitudes began to change as the industry finally came to terms with the realities of the new competitive era. Over time, electric utilities came to regard the power marketers as a cornerstone in the new competitive environment. Not only did they begin to invest in the creation of their own marketing arms, they had to live with the realization that the power marketers brought in a level of sophistication that far surpassed that of the utilities. Through their wide network of customers, power marketers offered utilities a convenient outlet for shifting business risks too broad to handle internally. In a relatively short time dealing in bulk power, the marketers developed an unrivaled ability to trade electricity as a commodity. Many utilities found that they had to match the sophistication with which the larger marketers handled electricity transactions. As a result, there is a growing trend among utilities to form strategic alliances with some of the most successful marketers. They are doing so in the hopes of better focusing on managing the risks associated with electricity distribution, while leaving the supply risks to their more sophisticated allies.

However, utilities still have to produce the electricity for the power marketers and approximately $10 \%$ of their operating costs are due to the cost of natural gas (Standard and Poors Industry Surveys: Electric Utilities 1998). Although this percentage is on the increase, only $7 \%$ of electric utilities are now dealing with natural gas futures (Silverstein 2000). The only fuel cost for electric utilities that is greater than natural gas is coal which is about $20 \%$ on the average above their cost of natural gas, but a futures market for coal is just being developed. In contrast, natural gas futures have been traded on the New York Mercantile Exchange (NYMEX) since 1990 and natural gas futures options have been traded on the NYMEX since 1993. These are American-style options that allow for exercise of the options anytime prior to expiration.

Before making a case for electric utilities to become more involved with natural gas futures and futures options to reduce risk, it is perhaps appropriate to digress into forwards and futures, and why futures are the preferred vehicles to use. A forward contract gives its holder both the right and full obligation to conduct a transaction involving natural gas at a predetermined future date and at a predetermined price. However, they are not securities in the traditional sense and are more appropriately viewed as trade agreements negotiated directly between two parties for a transaction scheduled to take place in the future. No collateral is required by either party so that a certain credit or default risk is involved.

One disadvantage of a forward contract is that it is quite often illiquid, meaning that it might be difficult or costly for a counter party to exit the contract before it matures. Illiquidity is really a by-product of the contractor's flexibility because the more specifically tailored an agreement is to the needs of a particular individual, the less marketable it will be to someone else. Futures contracts solve this problem by standardizing the terms of the agreement (e.g., expiration date, identity, and amount of the underlying natural gas) to the extent that it can be exchange traded. In contrast to the forward market, both parties trade through the NYMEX. Although the standardization of contracts reduces the ability of the ultimate end-users to select the most desirable terms, it creates homogeneity, whereby the counterparts can always unwind a previous commitment prior to expiration by simply trading their existing position back to the exchange at the prevailing market price. The NYMEX requires both counterparts to post collateral or margin to protect itself against the possibility of default. These margin accounts are held by the clearing house of the NYMEX. They are also marked-to-the-market (i.e., adjusted for contract price movements) on a daily basis to ensure that both end-users always maintain sufficient collateral to guarantee their eventual participation.

Thus the factors of liquidity and essentially a guarantee of performance make the futures contract the preferred vehicle of use. If the electric utilities themselves are reluctant to enter this futures market, the power marketers are not. An example is Reliant Energy (Silverstein 2000). Reliant Energy buys and sells 7 billion cubic feet of natural gas a day, representing $\$ 17.5$ million changing hands daily or more than $\$ 500$ million monthly. The 
futures market is much greater than that according to Patrick Strange, vice president of natural gas trading and marketing for Reliant Energy. Consider that commodities markets are generally 10 times the size of the physical market where the purchaser takes delivery of the actual product. The physical market for natural gas is now $\$ 60$ billion annually and is supported by a commodities market of $\$ 300$ billion with the energy industry just half way through deregulation.

The volatility in gas markets is enhancing the benefits of trading. In a regulated scenario, utilities bought energy on the spot market and passed their costs on to consumers. In a competitive environment, they can't do that and price is paramount. Some public service commissions are allowing utilities to hedge and to keep the resulting benefits, if any, and to accept the consequences of mistakes. Still, many regulatory bodies won't permit utilities to use futures to guard against price risks. Utilities are trying to figure out how to respond to the shifting rules and market conditions.

In most cases, Mitchell Energy's Dodd says "If they hedge and guess right, they must pass on the savings, but if they guess wrong, their shareholders may be at risk." This is part of the reason why NYMEX says that of those participating in gas futures, only about $7 \%$ are regulated utilities. For those utilities that are participating and will participate in the future, who should they be trying to emulate?

The electric power industry is at the juncture today where the banking industry was about 15 years ago. Ongoing deregulation of the electricity market is creating unprecedented uncertainty for the industry's decision makers. Deregulation means the influx of aggressive new players, intensification of competition, widening of customer choice, downward pressure on profit margins, and increase in the volatility of earnings. All these are familiar themes for those who lived through the banking deregulation of the 1970s. There are also parallels on the product side. There are a myriad of new products in the power markets and an increased usage of derivative instruments as hedging or trading tools. These new developments mean that the business environment is much riskier than it used to be. As a result, the development of sophisticated risk management tools becomes imperative.

Managers in the power industry are fortunate because many generic risk management tools have already been developed by their counterparts of the banking industry. Substantial knowledge and technology transfer from the banking industry to the utilities industry has occurred. For one thing, several progressive energy trading firms and forward-thinking utilities have acquired derivatives and financial engineering talent from Wall Street and the energy trading complex. Also, a few prominent consulting firms and software developers who have a long and successful track record of serving the financial community are adapting their skills and repackaging their products to capitalize on the new opportunities available in the power industry.

Thus the electric utilities have a model to follow in the banking industry and it would be well to recapitulate the evolution of financial engineering, the tool that the banking industry is using, during the last 20 years. Financial engineering is the theoretical foundation for understanding today's financial/commodity markets. Physical scientists and engineers, as well as mathematicians, have brought with them a high level of understanding of mathematics, statistics, and physics to financial engineering. These disciplines have been applied to create valuable complex financial products, such as exchange-traded or synthetic instruments, which allocate risk more effectively in the financial/commodities markets.

The most explicit example of this transition in the way financial markets are interpreted today is reflected in the options markets and the understanding of derivative instruments. It should be mentioned that the importance of options goes well beyond the profit-motivated trading that is most visible to the public. Options research has advanced in step with the exploding options market. Scholars have found that there is an options way of thinking in the financial decision-making process through the use of an options framework.

Options theory is based on an arbitrage agreement, which assumes that investors have a single period time horizon and are risk averse, the market is perfectly competitive, arbitrage causes the market to be in equilibrium, and actual return for an investment is a linear function of its expected return and an unspecified number of undefined risk factor measures. 
Furthermore, there are theoretical difficulties in applying options, such as deciding how to model random prices that determine the underlying asset value if the futures price is unknown. The only way to price flexibility is to characterize this unknown future by a stochastic process that assigns probabilities to possible future events over time. There are a variety of "random walks" that can be used. These random walks, or random processes, can be thought of as an "event" tree that branches out over time, the simplest tree being a binomial model in which there are two future possibilities for every current possibility at any point in time.

Fischer Black and Myron Scholes developed their option pricing model (OPM) using the assumptions that asset prices adjust to prevent arbitrage, that stock prices change continuously, and that securities follow a log-normal distribution. The model was also based on European stock options. The mathematics used to derive the formula are the random walk and calculus. The form of the Black-Scholes option pricing model is very close to a binomial distribution. As pointed out by Nedia Miller in her article in the book by Fusaro [1998], the problem with option pricing models is that we always have to make some type of assumptions, such as assumptions about future distribution of the forward price, assumptions about the way security prices move with time, assumptions about the correlation between forward rates and interest rates, or assumptions about the normal distribution of option prices.

Most of the time, these assumptions are off-track and lead to mispricing options. For example, the use of the Black-Scholes option pricing model over time has repeatedly confirmed that this model undervalues call options and overvalues put options, respectively. If we knew the amount by which these premiums were under/overvalued, we could resolve the problem quickly by adding or subtracting the appropriate amounts. The real problem is that we cannot quantify the difference.

This particular shortcomings of the Black-Scholes option pricing model arise from the fact that expected volatility remains unknown, even if we accept all the other assumptions of the model. As a result, a number of extensions of the Black-Scholes option pricing model have followed since 1973 which use two different pricing methods: (1) variations of the Black-Scholes option pricing model and (2) the binomial model. Nevertheless, scholars still have not found a perfect option pricing model that eliminates the original problem of not being able to estimate the volatility.

There are two basic approaches to estimating the volatility. The first approach is to use historic volatility to estimate the expected volatility. The second approach is to use fresh data from the options market itself. The second method uses option prices to find the option markets' estimate of the underlying commodity price's standard deviation. An estimate of the underlying commodity price's standard deviation that is drawn from the option market is called "implied volatility."

The above synopsis of the present situation for electric utilities was taken mainly from information from several articles in the book of Fusaro [1998]. As noted in the review of this book by Tim Evans [1988], the book "is weak in the area of practical risks and hidden costs." Because of the uncertain position of electric utilities and hedging strategies, perhaps the best way to evaluate their potential is to quantitatively evaluate their gains over no hedging during a time of particularly intense natural gas price volatility. This is the goal of the next section.

\section{ANALYSIS OF A NATURAL GAS PRICE VOLATILITY SCENARIO AND DEVELOPMENT OF APPROPRIATE HEDGING STRATEGIES TO LIMIT RISK}

Gas futures on the NYMEX are sold in units of 10 MMBtu and a contract typically sells in the range of $\$ 1800-3600$. The tick size in whose terms the price is quoted is $0.01 \mathrm{MMBtu}$ or one thousandth of a future unit so that the price generally lies in the range \$1.80-3.60. A graph of this price for near term futures for the market of late 2000 - early 2001 is shown in Fig. 1. Near term futures means futures for either the month following purchase up to the $25^{\text {th }}$ day of the month or two months following purchase and the price is an average of these two possibilities. Rolled over daily means this price averaged over a day. The horizontal dashed lines and lettering are for a technical analysis and will not be discussed here. 
For our purposes it is sufficient to note the vertical lines topped by arrows and bottomed by numbers which are seven dates of interest. Date 1 is Sept. 25 when the price starts to rise. Date 2 is Oct. 25 when the upward trend is confirmed despite some upward roll gaps which means small downs or gaps in the general trend. Date 3 is Dec. 3 when a major drop has occurred and intense volatility is evident. Date 4 is Dec. 17 when the peak is reached at 4.60. Date 5 is Dec. 31 when a second valley is reached. Date 6 is Jan. 6 when a second peak is reached. Date 7 is Feb. 10 when the price has returned to its Date 1 level.

A good financial manager is going to be doing two things: First, he/she is going to be buying futures to insure a continuous supply of natural gas to his/her utility. However, there is no guarantee that the amount saved by this technique will be sufficient to offset the increased cost of natural gas. Therefore, he/she secondly will buy and sell additional futures and futures options to make a profit which will hopefully be sufficient or more than sufficient to cover the increased cost of natural gas.

The first activity is fairly simple. While a future can be delivered at any day during the month it becomes due, for simplicity it will be assumed that it will be delivered on the $15^{\text {th }}$ day of the month that it becomes due. A manager picks a day or days during a month and consistently buys futures for delivery one or two months ahead. Because he/she can buy two months ahead, if buying is carried out on only one day per month, he/she can skip a buying day every other month if that appears desirable. There is no guarantee that this procedure will result in a net saving, but it has the potential for doing so. Certainly it reduces supply risk by locking in the future price some time in advance.

The profit making activity is more complicated and it is now outlined for the specific days on which actions should be taken. On Day 2 approximately the same number of futures the manager buys for supply purposes (quantity A) should be bought for profit making purposes. A long put should be bought for the same quantity A to reduce the risk if the price drops (long hedging). On Days 3, 4, 5, and 6 the manager should buy quantity A of futures for profit making purposes and quantity A of a long call and quantity A of a long put to reduce risk (long straddle) since it is unknown in which direction the market will go.

Having given general strategies for a manager for Fig. 1, it will now be shown how well they work with a specific numerical example. Suppose the manager works for a utility which has a need of $100 \mathrm{MMBtu}$ of natural gas which is ten futures contracts. It can be seen from Fig. 1 that an average cost without the bull market would be $\$ 2.20$ or $\$ 2200$ for 10 MMBtu or $\$ 22,000$ for 100 MMBtu. Thus to supply the utility for the 5 months from Nov. 15, 2000 to Apr. 15, 2001 the manager would normally expect to pay $\$ 110,000$.

The first hedging strategy the manager should enact is to buy futures to insure a continuous supply. Suppose that he/she makes the following purchases starting on Day 1 or Sept. 25.

Date $\underline{\text { Action }}$

Sept. 25 Buy 10 Nov. 15 and 10 Dec. 15 futures for $\$ 21,000$ for each 10 futures

Oct. $25 \quad$ Buy 10 Jan. 15 futures for $\$ 27,500$

Nov. $25 \quad$ Buy 10 Feb. 15 futures for $\$ 34,000$

Jan. $25 \quad$ Buy 10 Mar. 15 futures for $\$ 25,000$

The actual spot prices for $100 \mathrm{MMBtu}$ on these days were:

$\underline{\text { Date }}$

$\underline{\text { Price }}$

Nov. 15

Dec, $15 \quad \$ 46,000$

Jan. $15 \quad \$ 32,000$

Feb. $15 \quad \$ 20,000$

Mar. $15 \quad \$ 19,000$ 
By combining these prices with the above purchases, one sees that the manager saved money as compared to the spot price for the first three purchases and lost money relative to the spot price for the last two purchases, but still saved $\$ 14,500$. The cost of the 5 purchases was $\$ 128,500$ or $\$ 18,500$ more than the normal price that he would have paid without the bull market of $\$ 110,000$ (see the previous paragraph). Thus there is some motivation for not only buying futures, but also developing a profit making strategy to counteract the additional cost of gas.

Does the strategy suggested above for the manager's profit making activity really work? Suppose for simplicity that the premium for one futures put or call is $\$ 300$ which is in fact at the upper limit of the range of options premiums for natural gas and that they expire on the last day of the options month. Suppose that the manager makes the following purchases and sales (outflow is indicated by a - sign, inflow by a + sign):

$\underline{\text { Date }}$

Oct. 25

Dec. 3

Dec. 17

Dec. 31

Jan. 6

Dec. 17

Dec. 31

Jan. 6

Feb. 10

\section{$\underline{\text { Activity }}$}

Buy 10 Jan. 15 futures

$-27,500$

Buy 10 Jan. 15 futures 2.75 puts Jan.

Buy 10 Jan. 15 futures

Buy 10 Jan. 15 futures 3.40 calls Jan.

Buy 10 Jan. 15 futures 3.40 puts Jan.

Buy 10 Jan. 15 futures

Buy 10 Jan. 15 futures 4.60 calls Jan.

Buy 10 Jan. 15 futures 4.60 puts Jan.

Buy 10 Feb. 15 futures

Buy 10 Feb. 15 futures 2.70 puts Feb.

Buy 10 Mar. 15 futures

Buy 10 Mar. 15 futures 3.50 calls Mar.

Buy 10 Mar. 15 futures 3.50 puts Mar.

Sell 20 Jan. 15 futures

Exercise 3.40 Jan. call

Exercise 4.60 Jan. put

Sell 10 Feb. 15 futures

Exercise 2.70 Feb. call

Exercise 3.50 Mar. put
Buy 10 Jan. 15 futures

Sell 10 Jan. 15 futures

Sell 10 Jan. 15 futures

Buy 10 Feb. 15 futures

Sell 10 Feb. 15 futures

Sell 10 Mar. 15 futures

Net profit
$-3,000$

$-34,000$

$-3,000$

$-3,000$

$-46,000$

$-3,000$

$-3,000$

$-27,000$

$-3,000$

$-35,000$

$-3,000$

$-3,000$

$+92,000$

$-34,000$

$+46,000$

$+46,000$

$+35,000$

$-27,000$

$+35,000$

$+35,000$

$+31,500$

Adding the positive and negative amounts leads to a net gain of $\$ 31,500$. Because the options charges were taken at the upper limit of their normal range, no commissions or interest charges have been deducted. When the $\$ 18,500$ additional cost over the normal cost without the bull market is deducted from the $\$ 31,500$ profit making result (see the previous paragraph), there is still a surplus of $\$ 13,000$.

Thus the combination of hedging for supply purposes and conservative hedging with all risks fully covered for profit making purposes would serve the manager well. The $\$ 13,000$ net surplus over his/her average costs is 59\% of his/her normal cost of $\$ 22,000$ for a one month supply of natural gas, so no unreasonable profit has been made.

\section{CONCLUSIONS}

A very strong case has been presented for why the financial manager of an electric utility company should use hedging strategies to ensure a continuous supply of natural gas to his/her utility. A futures market in electric power itself is also traded on the NYMEX and the same types of strategies could be used to insure that the utility always has adequate quantities of excess power. Since these futures have only existed since March 29, 1996, the natural gas market was chosen for analysis in this paper since there are many more cases from which to choose. 
However, as compared to a normal volatility of $40 \%$ in natural gas futures, the volatility in electric power futures has been running at $50 \%$. Thus the hedging strategies given in this paper are even more necessary in this case.

It should be emphasized that the strategies in Section 3 consist of two activities: 1 . Buying futures to insure a continuous supply of natural gas to the utility. 2. Buying futures for profit making with minimized risk by using long hedging and long straddle options buying. It is interesting to note that in the numerical example neither activity alone would have been sufficient to keep the cost at the nominal cost of $\$ 22,000 /$ month. If only the first activity were used, even though $\$ 14,500$ was saved over the spot price, $\$ 18,500$ more was still paid for gas for this five month period compared to the nominal cost of $\$ 110,000$. If only the second activity was used, even though $\$ 31,500$ was made in profit, when this is subtracted from the $\$ 33,000(\$ 14,500+\$ 18,500)$ additional cost, a net deficit of $\$ 1,500$ would still have to be covered. There is no implication that these results would be the same in every case, but it can be expected that using both strategies astutely will almost always be better than using one only.

A natural question is why the financial manager should or should not engage in more profit making activities? There is no implication that the amount of profit making activity has been optimized, but two points could be stated: 1 . There is still a cost for call and put options premiums and there is no guarantee that the market will always be as volatile as in the case above. Smaller volatility would have resulted in lower profits. 2 . There is certainly an ethical question of whether the manager has any valid need to do more profit making than would be necessary to keep his/her costs at their nominal level.

In summary a combination of hedging strategies has been presented and tested for the natural gas market. The combination of strategies works and works well while substantially reducing risk at the same time.

\section{REFERENCES}

1. Evans, T. 1998, Futures, 27, 86. "Energy Risk Management: Hedging Strategies and Instruments for the International Energy Markets.”

2. Fusaro, P. C. 1998, Energy Risk Management, Mc-Graw Hill, New York.

3. $\quad$ Silverstein, K. 2000, Utility Business, 3, 40. "Gas Trading Gets Hot."

4. $\quad$ Standard and Poors Industry Surveys: Electric Utilities 2000. 
Notes 